\title{
Reconstruction of environmental and climatic changes in the Paleo-Kathmandu Lake during the last 700 ka: An approach from fossil-diatom study
}

\author{
Tatsuya Hayashi†*, Harutaka Sakai†, Yoshihiro Tanimurał, Hideo Sakai§, Wataru Yahagi§ and Masao Uchida 『 \\ † Department of Earth Sciences, Kyushu University, Ropponmatsu, Fukuoka, 810-8560, JAPAN \\ ‡ Department of Geology, National Science Museum, Tokyo 169-0073, JAPAN \\ $\$$ Department of Earth Sciences, Toyama University, Gohuku, Toyama, 930-8555 JAPAN \\ I Japan Marine Science and Technology Center, Yokosuka, 237-0061 JAPAN \\ *To whom correspondence should be addressed.E-mail: cs501034@scs.kyushu-u.ac.jp
}

Terrestrial paleoclimatic and paleoenvironmental records on the Indian monsoon are extremely limited, though many investigations have been done on the deep-sea sediments in the Indian Ocean during the last few decades. In order to clarify the terrestrial monsoonal climatic records during the Quaternary, we undertook core-drilling of the basin-fill sediments of the KathmanduValley, which is located under Indian monsoon zone. In this paper, we attempt to reconstruct the environmental changes of the Pakeo-Kathmandu Lake, on the basis of studies on the fossil-diatom collected from a 218-m-long core drilled at Rabibhawan, western central part of Kathmandu.

Except the uppermost thin cover of fluvial sediments (Patan Formation), the core is continuous and mainly composed of muddy lacustrine sediments (Kalimati Formation) containing abundant fossil-diatoms, which document ecological responses to climatic and environmental changes (Sakai 2001, Hayashi et al. 2002). Mud samples were collected at $50 \mathrm{~cm}$ interval from 7 to $45.5 \mathrm{~m}$ in depth and at $2 \mathrm{~m}$ interval from 47.5 to $218 \mathrm{~m}$ in depth. We identified each species and counted the number of valves by means of a scanning electron microscope (JSM-5600) at $\mathrm{x} 5,000$ magnification, because dominant species in the RBcore are very small, ranging from 5 to $30 \mu \mathrm{m}$. For each sample, at least 300 diatom valves were counted.

On the basis of relative abundance and the number of principal diatoms, eight fossil zones and three subzones in zone 2 were defined in the Kalimati Formation (Figure 1). Zone 8 at the basal part is characterized by variety of diatom assemblages and relatively low number of diatom valves, which reflect marsh or very shallow-water environments. Based on water-level indicators (ratio of planktonic diatoms to benthic diatoms and frequency of genus Aulacoseira), the water-level seems to have deepened gradually from zone 8 to zone 7 , and retained deep condition from zone 6 to zone 4 . Zones 6 to 4 are characterized by monodominance of Cyclotella: Cyclotella sp. 1 is a characteristic in zone 5, and Cyclotella sp. 2 is in zone 6 and zone 4. Number of their valves is very abundant. On the other hand, in zone 3 and zone 2, there are several dominant species and number of total diatom valves decreases. Furthermore, ratio of planktonic diatoms to benthic diatoms periodically rises and falls, which probably indicates water-level fluctuations. Especially in zone 2A, fluvial and marsh environments were expanded in marginal area of the lake, because relative abundance and number of Staurosira construens and Pseudostaurosira brevistriata, indicative species for marsh environment, become high. In zone 1, ratio of planktonic diatoms increases, which indicates the water-level rose again. But after zone 1, number of total diatom valves drastically reduces. It demonstrates that the lake was drained during a short period at about $12 \mathrm{ka}$.

Comparison of environmental changes of the PaleoKathmandu Lake with $\delta^{18} \mathrm{O}$ record from a core MD900963 collected in the Indian Ocean (Bassinot et al. 1994) for the past $630 \mathrm{ka}$, shows that the water-level of the Paleo-Kathmandu Lake seems to have fallen at glacial age (MIS 14, 10, 8, 6, 2). We recognized following five major events expressed by high ratio of benthic diatoms, which indicate lowering of water-level. According to the time-scale derived from paleomagnetic study and $\mathrm{AMS}{ }^{14} \mathrm{C}$ dating of the core, the following stages correspond to marine isotope stages (MIS) from MIS 14 to MIS 2.

Zone $5 \sim$ zone $4=$ MIS 14

Early stage of zone $3=$ MIS 10

Later stage of zone $3=$ MIS 8

Later stage of zone $2 \mathrm{C}=\mathrm{MIS} 6$

Later stage of zone $2 \mathrm{~A}=$ MIS 2

It is likely that these environmental changes of the PaleoKathmandu Lake mainly caused by fluctuations of Indian monsoon related to global climatic changes (glacial-interglacial cycle).

\section{References}

Bassinot FC, LD Labeyrie, E Vincent, X Quidelleur, NJ Shackleton and Y Lancelot. 1994. The astronomical theory of climate and the age of the Brunhes-Matuyama magnetic reversal. Earth Planet Sci Lett 126: 91108

Hayashi T, YTanimura and H Sakai. 2002. A preliminary report on the study of fossil diatoms in the drilled core from the Paleo-Kathmandu Lake. Chiky Monthly 24: 359-362

Sakai H. 2001. Stratigraphic division and sedimentary facies of the Kathmandu Basin Group, central Nepal. J Nepal Geol Soc 25: 19-32 


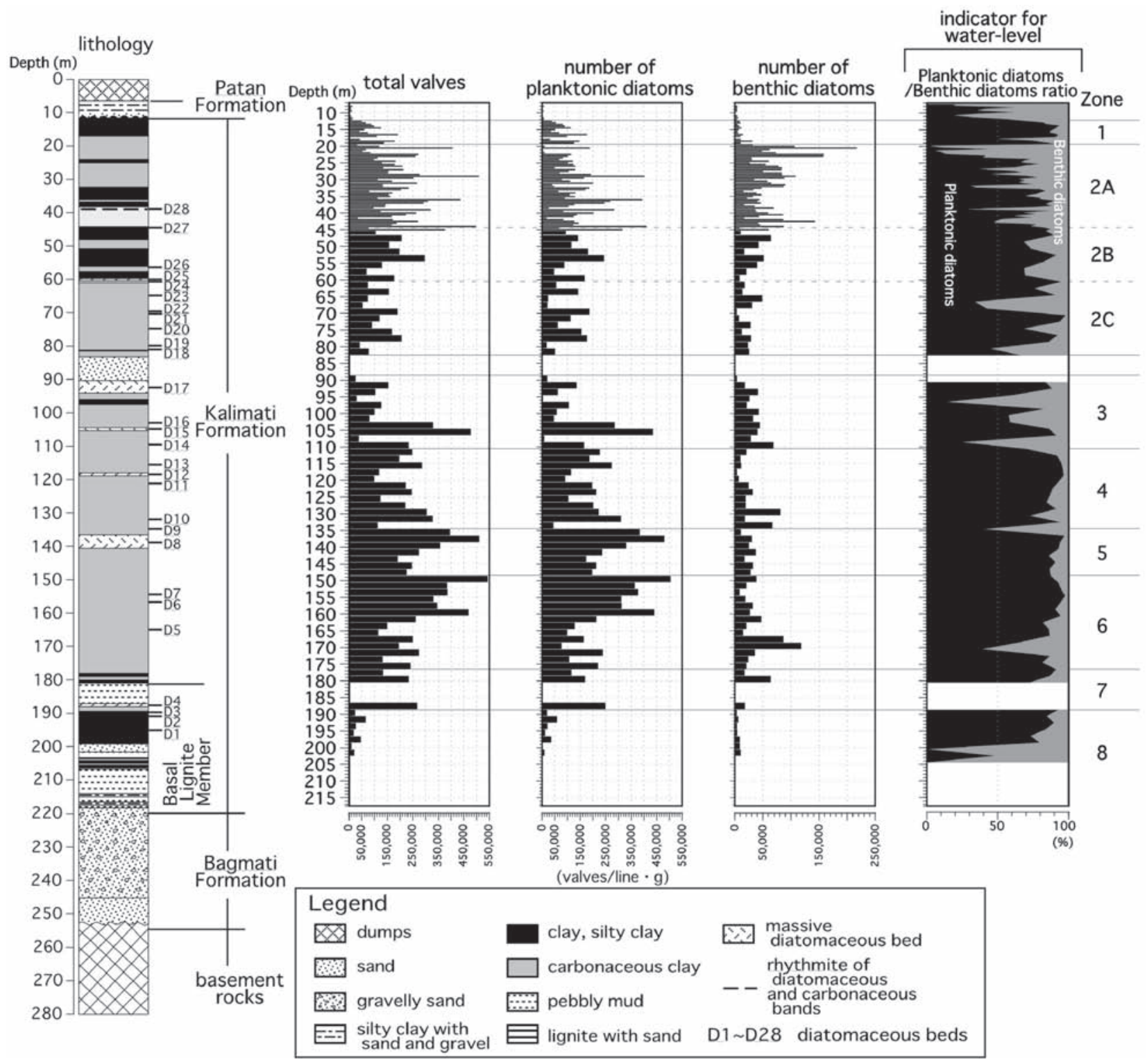

FIGURE 1. Histograms of number of total valves and ratio of planktonic diatoms to benthic diatoms. Lithostratigraphy of RB-core is shown on the left 